\title{
Communication
}

\section{Interaction of class A G protein-coupled receptors with G proteins ${ }^{\star \star}$}

\author{
Rafał Ślusarz and Jerzy Ciarkowski ${ }^{\bowtie}$
}

Faculty of Chemistry, University of Gdansk, Gdansk, Poland

Received: 31 October, 2003; revised: 01 February, 2004; accepted: 04 March, 2004

Key words: GPCR class A, G protein, GPCR activation

\begin{abstract}
A model for interaction of class $A G$ protein-coupled receptor with the $G$ protein $G_{\alpha}$ subunit is proposed using the rhodopsin-transducin $(\mathrm{RD} / \mathrm{Gt})$ prototype. The model combines the resolved interactions/distances, essential in the active $\mathrm{RD}^{*} / \mathrm{Gt}$ system, with the structure of $\mathrm{Gt}_{\alpha} \mathrm{C}$-terminal peptide bound to $\mathrm{RD}^{*}$ while stabilizing it. Assuming the interactions involve conserved parts of the partners, the model specifies the conserved Helix 2 non-polar X- - X, Helix 3 DRY and Helix 7/8 NP- -Y- - F RD* motifs interacting with the $\mathbf{G t}_{\alpha} \mathrm{C}$-terminal peptide, in compliance with the structure of the latter. A concomitant role of $\mathbf{G t}_{\alpha}$ and $\mathbf{G t}{ }_{\gamma} \mathbf{C}$-termini in stabilizing $\mathbf{R D}^{*}$ could possibly be resolved assuming a receptor dimer as requisite for $\mathrm{G}$ protein activation.
\end{abstract}

GDP-binding (G) protein-coupled receptors (GPCRs) are single-chain integral membrane proteins, composed of a heptahelical transmembrane (7TM) domain and the exo- and endo-domains, made of inter-helical loops, with the $\mathrm{N}$ - and $\mathrm{C}$-termini, respectively. GPCRs, occupying about $3 \%$ of the human genome, mediate actions of about $50 \%$ used drugs making about $25 \%$ of the top-100-selling list (Klabunde \& Hessler, 2002). Activation of a GPCR upon binding an agonist consists of in allosteric structure rearrangement, transduced through the 7TM domain from the exo-side to the GPCR-G protein in-

\footnotetext{
${ }^{\star}$ Presented at the 17th Polish Peptide Symposium, August 31st-September 4th, 2003, Łódź, Poland.

This work was supported by the State Committee for Scientific Research (KBN, Poland) grants BW/8000-5-0220-3 and DS/8372-4-0138-4, and by the Academic Computer Center in Gdańsk TASK regarding the use of high power computers.

${ }^{凶}$ Corresponding author: Faculty of Chemistry, University of Gdansk, J. Sobieskiego 18, 80-952, Gdańsk, Poland; phone: (48 58) 345 0330; fax: (48 58) 341 0357; e-mail: jurek@chem.univ.gda.pl

Abbreviations: CL1-CL3, cytosolic(endo) loops 1-3; EL1-EL3, exo loops 1-3; G protein, GDP-binding protein; GPCR, G protein-coupled receptor; MD, molecular dynamics; MII or RD*, Meta II (activated) form of RD: rhodopsin; PDB, Protein Data Bank; 7TM, heptahelical transmembrane domain; TM1-TM7, transmembrane helices 1-7.
} 
terface on the cytosolic (endo-) side. Its molecular mechanism is unknown, in contrast to the reasonably well established activation mechanism of $\mathrm{G}_{\alpha \beta \gamma}$ subtypes (Noel et al., 1993; Lambright et al., 1994; 1996). The GPCR $\rightarrow$ G protein activation seems to be a common mode in otherwise diverse cascades of signal transduction from miscellaneous extracellular media to the cytosol. A great impetus to the GPCR research was added by the solving of the first historical structure of their representative, that of dark-adapted (inactive) rhodopsin (RD) (Palczewski et al., 2000; Teller et al., 2001; Okada et al., 2002), triggering a number of new comments and reviews on possible signal transduction mechanism and GPCR activation (e.g.: Okada \& Palczewski, 2001; Okada et al., 2001; Hamm, 2001; Sakmar, 2002; Meng \& Bourne, 2001; Ballesteros \& Palczewski, 2001; Lu et al., 2002; Stenkamp et al., 2002; Koenig, 2002; Hunyady et al., 2003; Filipek et al., 2003a; 2003b; Cherfils \& Chabre, 2003; Mirzadegan et al., 2003) and stimulating work to elucidate this mechanism (e.g.: Altenbach et al., 2001; Ballesteros et al., 2001; Arimoto et al., 2001; Aris et al., 2001; Koenig et al., 2002; Bissantz et al., 2003; Fritze et al., 2003; Kisselev \& Downs, 2003; Liang et al., 2003).

Despite some doubts a few aspects regarding details of GPCR activation seem widely agreed upon. Firstly, there is an agreement as to the common activation mechanism for Family A members, highlighting a role of conservative residues, accompanied with a strong confidence that the RD structure makes a good template for the whole Family A GPCRs (Okada \& Palczewski, 2001; Okada et al., 2001; Hamm, 2001; Meng \& Bourne, 2001; Ballesteros \& Palczewski, 2001; Ballesteros et al., 2001; Sakmar, 2002; Lu et al., 2002; Stenkamp et al., 2002; Koenig, 2002, Hunyady et al., 2003; Filipek et al., 2003a; 2003b; Mirzadegan et al., 2003; Fritze et al., 2003; Bissantz et al., 2003), see, however, a disagreement with the above view (Ar- cher et al., 2003). Secondly, an agreement as to the opening, upon agonist-triggered activation, of the cytosolic GPCR domain into a cavity, capable of accommodating selected interacting fragments of the $\mathrm{G}$ protein at the receptor-G protein interface. It is proven that the cavity results from an outward movement of the TM 6 cytosolic side by about $8 \AA$, and those of TM7 and TM2, with accompanying loops, by about 2-3 $\AA$ (Farrens et al., 1996; Altenbach et al., 2001). Thirdly, it is known from two independent NMR studies (Kisselev et al., 1998; Koenig et al., 2002) that the $\mathrm{Gt}_{\alpha}$ C-terminal undecapeptide $\mathrm{Gt}_{\alpha}(340-350)$ - essential for stabilization of activated RD (RD*, Meta II, MII) - converts into an $\alpha$-helix in the presence of $\mathrm{RD}^{*}$. Thus, the structure of this peptide, unresolved in solid-state Gt (Noel et al., 1993; Lambright et al., 1994; Lambright et $a l ., 1996)$, makes a natural extension of $\alpha 5$ in $\mathrm{Gt}_{\alpha}$ forming a tip, potentially capable of fitting into a cavity in $\mathrm{RD}^{*}$ at the receptor-Gt interface. It is known that this undecapeptide, likewise a $\mathrm{C}$-terminal $\mathrm{Gt}_{\mathrm{t}}$-farnesyl peptide, stabilizes RD* (Hamm et al., 1988; Martin et al., 1996; Aris et al., 2001). Finally, the structure of this C-terminal Gty, (60-71)farnesyl peptide in a complex with $\mathrm{RD}^{*}$ has just been elucidated to be an amphipathic helix, likely placed on the bilayer surface in its interfacial region (Kisselev \& Downs, 2003). Thus, in this work, assuming a possible complement between the $\mathrm{Gt}_{\alpha}$ tip and the $\mathrm{RD}^{*}$ cavity, we attempt to prove that in any receptor $-G_{\alpha}$ system an arrangement is possible, involving conservative residues of both parties in equivalent sets of interactions. To this aim, commonly approved general arrangements between $\mathrm{G}_{\alpha}$ and receptor are assumed (Onrust et al., 1997; Bourne, 1997; Iiri et al., 1998; Hamm, 2001; Koenig et al., 2002; Sakmar, 2002; Lu et al., 2002). It is also shown that a parallel, simultaneous or sequential accommodation of both $\mathrm{Gt}_{\alpha}$ (Aris et al., 2001; Martin et al., 1996) and Gty (Kisselev et al., 1999; Ernst et al., 2000) C-terminal peptides interacting with the same $\mathrm{RD}^{*}$ 
molecule is hardly possible, unless an $\mathrm{RD}^{*}$-dimer (oligomer) is assumed.

\section{METHODS}

Starting coordinates for all heavy atoms of dark-adapted $\mathrm{RD}$ were obtained from the X-ray data (Palczewski et al., 2000), entry $1 \mathrm{f} 88$ in the Protein Data Bank (PDB) (Berman et al., 2000). Having sealed the first gap in the structure (236-239; using SYBYL (1999) program) we ignored the C-terminal end of the sequence (beyond the second unresolved gap) so that in this work we used the unbroken RD sequence $1-327$, terminating 6 and 4 residues C-terminal to the peripheral cytosolic Helix 8 and C323-palmitoyl anchor of putative cytosolic loop 4 (CL4), respectively. The resulting structure is free of most of surface obstacles (e.g. the S334-A348 C-terminal plug, seen in the dark RD) for a smooth RD*-Gt interface and conditioned for a potential cavity, capable of receiving the $\mathrm{C}$-terminal helical $\alpha 5$ extension. Subsequently, the retinylidene at- al., 1997). Using target-driven $\mathrm{MD}$, the cytosolic side of $\mathrm{RD}$, beginning from helix-breaking hinges (G89-G90 in TM2, P267 in TM6 and retylidene-K296 in TM7), was forcefully modified, so that the set of ultimate distances between the cytosolic ends of TM2-TM3, TM7-TM3 and TM6-TM3 approximately met those agreed upon and recommended in the literature (Altenbach et al., 2001; Arimoto et al., 2001). The specific constraints and procedures were elaborated in trial-and-error repeats and resulted in an algorithm consisting of a 30 ps severely constrained MD in vacuo at room temperature, with the constraints listed in Table 1. After this target-driven MD, the structure was energy-minimized to remove close van der Waals contacts and considered as a crude $\mathrm{RD}^{*}$ model ready for further use. Its molecular electrostatic potential surface at the $\mathrm{RD}^{*}-\mathrm{Gt}_{\alpha \beta \gamma}$.GDP interface is shown in Fig. 1, bottom.

The complete $\mathrm{Gt}_{\alpha}$ subunit was modeled through a fusion of the Gt $\alpha \beta \gamma$.GDP structure (PDB entry 1got) with the $\mathrm{Gt}_{\alpha} \mathrm{C}$-terminal

Table 1. Constraints elaborated for $30 \mathrm{ps}$ MD in vacuo to bring the starting $\mathrm{RD}^{*}$ structure to meet structural features drawn in the literature (Altenbach et al., 2001; Arimoto et al., 2001)

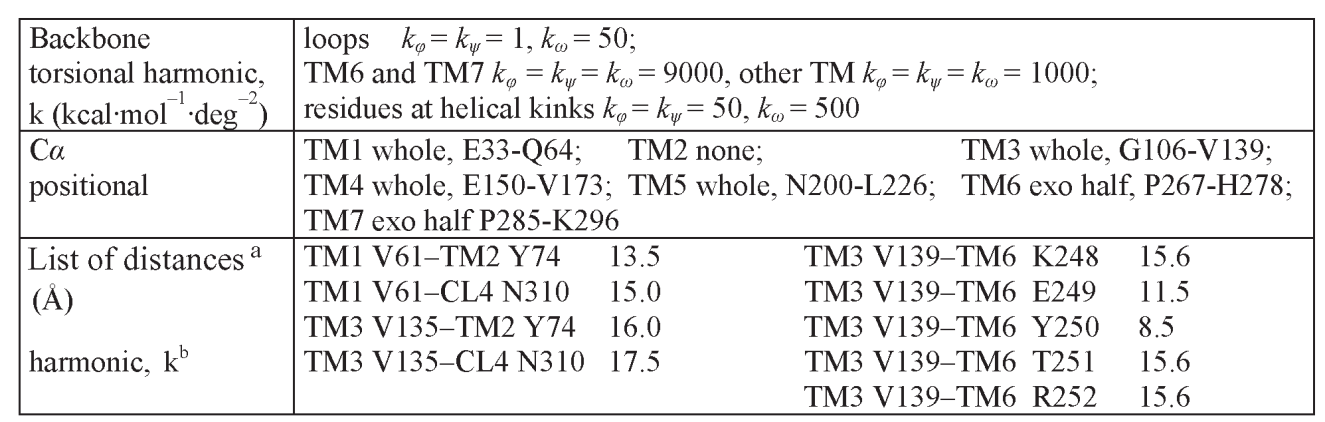

${ }^{\mathrm{a}} \mathrm{C} \alpha$-C $\alpha$ based; ${ }^{\mathrm{b}}\left(\mathrm{kcal} \cdot \mathrm{mol}^{-1} \cdot \AA^{-2}\right)$ linearly increasing during $30 \mathrm{ps}$ simulation from 900 (start) to 3000 (end).

tached through a Schiff-base nitrogen at K296 in TM7, was set all-trans while the charges at D83 (TM2), E113, E122, E134 (TM3) and K296 (TM7) were set neutral, typical of MII state (Fahmy et al., 1993; Okada et al., 2001; Saam et al., 2002; Röhrig et al., 2002). The retinal was parameterized as recommended in the AMBER manual (Case et
340-350 undecapeptide (PDB entry 1aqg) in a complex with $\mathrm{RD}^{*}$ (Kisselev et al., 1998), via their overlapping region I340-K-E342 and subsequent elimination of double residues from this region. The complete $\mathrm{Gt}_{\alpha \beta \gamma}$.GDP was energy-minimized to remove van der Waals clashes, and as such ready for further use. Its molecular potential surface at the 
$\mathrm{RD}^{*}-\mathrm{Gt}_{\alpha \beta \gamma}$.GDP interface is shown in Fig. 1, top.

The docking of both structures was guided by the established view on how they would mutually complement at their interface (Bourne, 1997; Onrust et al., 1997; Iiri et al., 1998; Oliveira et al., 1999; Hamm, 2001; tween selected amino-acid residues and a more general complementarity between the $\mathrm{RD}^{*}$ endo-cavity and the $\mathrm{Gt}_{\alpha \beta \gamma}$. GDP tip as well as the recommended mutual overall interface, including extended specific interactions and surface electrostatic potential complement (Onrust et al., 1997; Hamm, 2001;

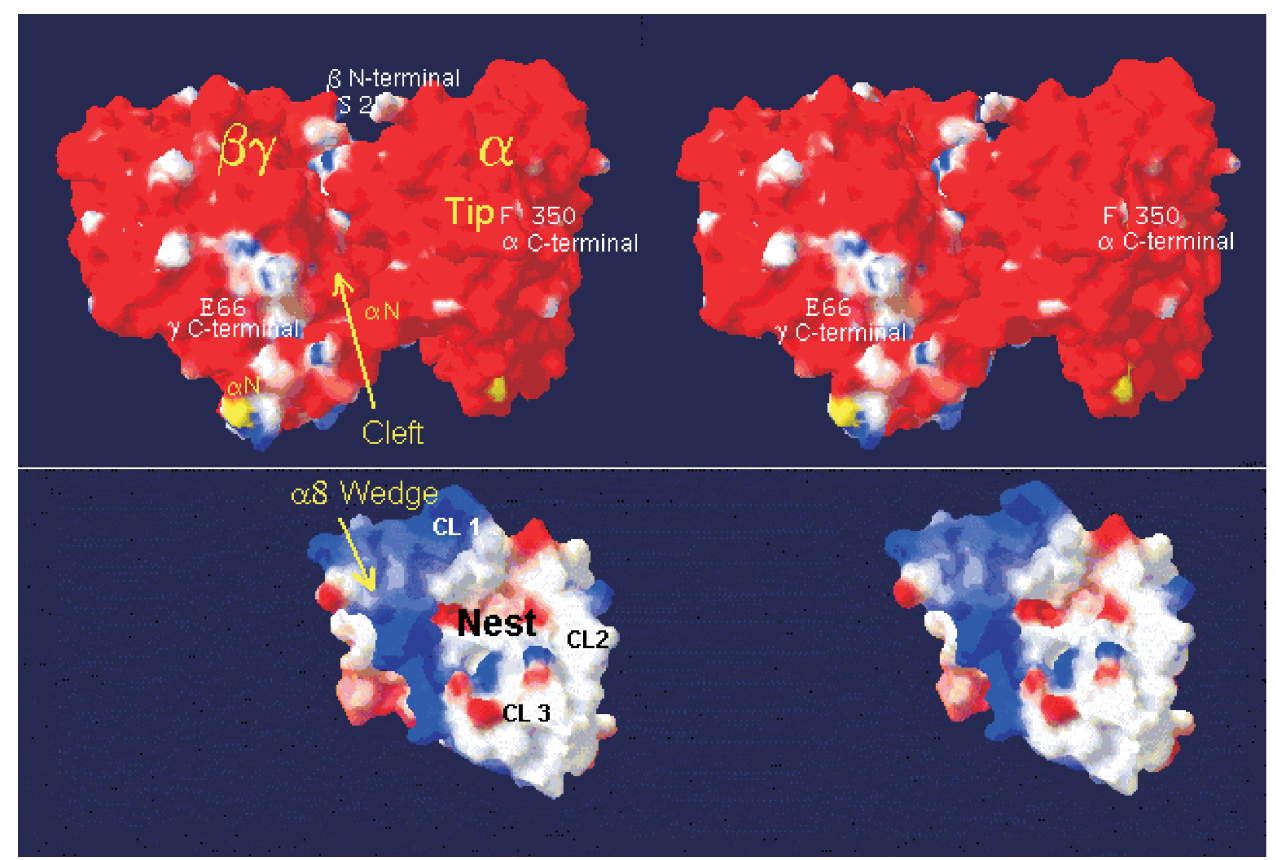

Figure 1. Electrostatic potential in stereo, calculated using protonation/dissociation states typical of $\mathrm{pH}$ 7 for basic/acidic amino acids respectively, and the resulting GROMOS96 point atom charges (van Gunsteren \& Berendsen, 1996) for all amino acids, as implemented in SPDBViewer program.

The potential is mapped on the molecular surface: red -1.8, white 0, blue 1.8 (in kT/e units). Top: Gt $\alpha \beta \gamma$.GDP interface; bottom: $\mathrm{RD}^{*}$ interface. The interface clearly indicates the vast excess negative potential on the $\mathrm{Gt}_{\alpha \beta \gamma}$ surface complementary to an excess positive potential at the $\mathrm{RD}^{*}$ surface. For reference, the visible $\mathrm{N}$ - and C-terminal residues of the $\mathrm{Gt}_{\alpha}, \mathrm{Gt}_{\beta}$ and $\mathrm{Gt}_{\gamma}$ subunits are labeled accordingly. So are other distinct features in the both proteins. Folding top-to-bottom along the white line hinge roughly satisfies the Cleft-Wedge and the Tip-Nest fits and produces the structure given in Fig. 2.

Koenig et al., 2002; Sakmar, 2002; Lu et al., 2002; Cherfils \& Chabre, 2003). Manual-visual docking was done using the SwissPDBViever package (Guex et al., 1999). Apart from the experimentally determined residues at the interface (Onrust et al., 1997; Iiri et al., 1998; Koenig et al., 2002) the mutual complement of electrostatic potential surface was assumed as a key factor (Oliveira et al., 1999; Hamm, 2001). Using manual trial and error docking with visual feedback, a reasonable mutual arrangement was reached, meeting both the specific interactions be-
Koenig et al., 2002), see Fig. 1. Finally, the $\mathrm{Gt}_{\alpha}$ C-terminal peptide 338-350 was left in the cavity, the complex was energy-minimized, immersed in a fully hydrated well equilibrated lipid bilayer model, the system heated and submitted to a long-term MD at room temperature. The united-atom OPLS (Jorgensen \& Tirado-Rives, 1988) force field as implemented in AMBER 5.0 was used. Currently, the MD has reached about 10000 ps (Ślusarz \& Ciarkowski, unpublished). Simultaneously, three other activated receptor- $G_{\alpha}$ C-terminal peptide systems were modeled, 
viz. V1aR-Gq/11, OTR-Gq/11 and V2R-Gs, for examination of their mutual complement and consistency.

\section{RESULTS AND DISCUSSION}

The manual docking of Gt to the $\mathrm{RD}^{*}$ model resulted in a complex shown in Fig. 2. Under the docking conditions described in Methods, a rather narrow margin has resulted for our trial-and-error. This is reasonable, given that complementary in terms of electrostatic potentials, see Fig. 1. Consequently, this interface exhausts most of both rotational and translational mutual freedom, leaving only some rotation of $\mathrm{RD}^{*}$ relative to $\mathrm{Gt}$ around a common vertical axis, see Fig. 2, if the suggested mutual interactions, e.g. those between $\mathrm{Gt}_{\alpha} \mathrm{N}$-terminus and RD* Helix $8 \mathrm{C}$-terminus, and others (Onrust et al., 1997; Bourne, 1997; Iiri et al., 1998; Hamm, 2001; Koenig et al., 2002; Lu et al., 2002) are to be preserved. It has become immediately clear

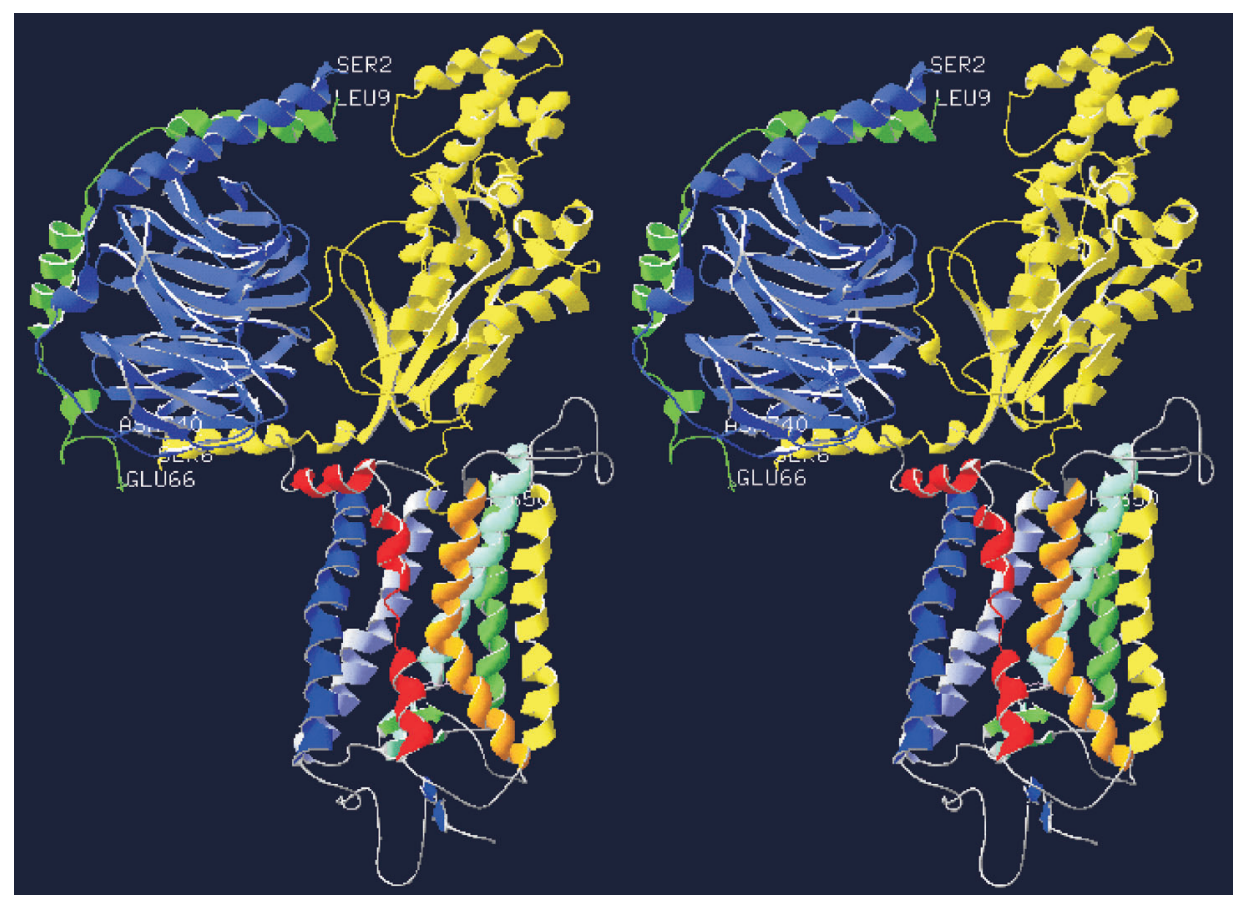

Figure 2. An outlook of the raw $\mathrm{RD}^{*}-\mathrm{Gt}_{\alpha \beta \gamma} \cdot \mathrm{GDP}$ complex, in stereo, meeting docking criteria discussed in the text.

The complex results from matching the interfacing surfaces, given in Fig. 1, by folding them at the white horizontal line, taken as a hinge, in Fig. 1. RD* (bottom) is colored according to the sequence progression, notice the break of

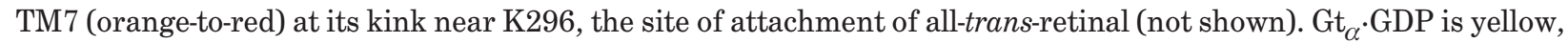
$\mathrm{Gt}_{\beta}$ blue and $\mathrm{Gt}_{\gamma}$ green. The N- and C-termini of the $\mathrm{Gt}_{\alpha \beta \gamma}$ subunits are labeled. For instance, Gt $\alpha$ starts with $\mathrm{S} 6$ at $\alpha \mathrm{N}$ in far left and ends with F350 nested in the RD* cavity at the receptor-Gt interface. Notice that for concomitant interactions of both $\alpha \mathrm{N}-\mathrm{CL} 3$ and $\mathrm{RD}^{*}-\mathrm{Gt}$, C-terminus, a second receptor molecule is needed, parallel to and at the rear-left position to the first one. The current 1:1 stoichiometry can at most be compatible with simultaneous interaction: $\mathrm{RD}^{*}$ with $\mathrm{Gt}_{\alpha}$ C-terminus and CL3 with $\mathrm{Gt}_{\alpha} \alpha 4-\beta 6$-loop, see text.

the rotational freedom of $\mathrm{RD}^{*}$ versus $\mathrm{Gt}_{\alpha \beta \gamma} \cdot \mathrm{GDP}$ is quite limited in view of the generally approved mutual position. This arrangement compromises the fit of the $\mathrm{Gt}_{\alpha}$ tip to the $\mathrm{RD}^{*}$ cavity with putative planes of interface, relatively smooth in both parties and that under these restraints the fit of the $\mathrm{Gt}_{\alpha}$ tip to the $\mathrm{RD}^{*}$ cavity is roughly compatible with three clusters of conservative interactions shown in Fig. 3: (i) a set of polar ionic interactions involving $\mathrm{Gt}_{\alpha}(340-350) \mathrm{K} 341$, K345, D346 and F350 C-terminal carboxylate 


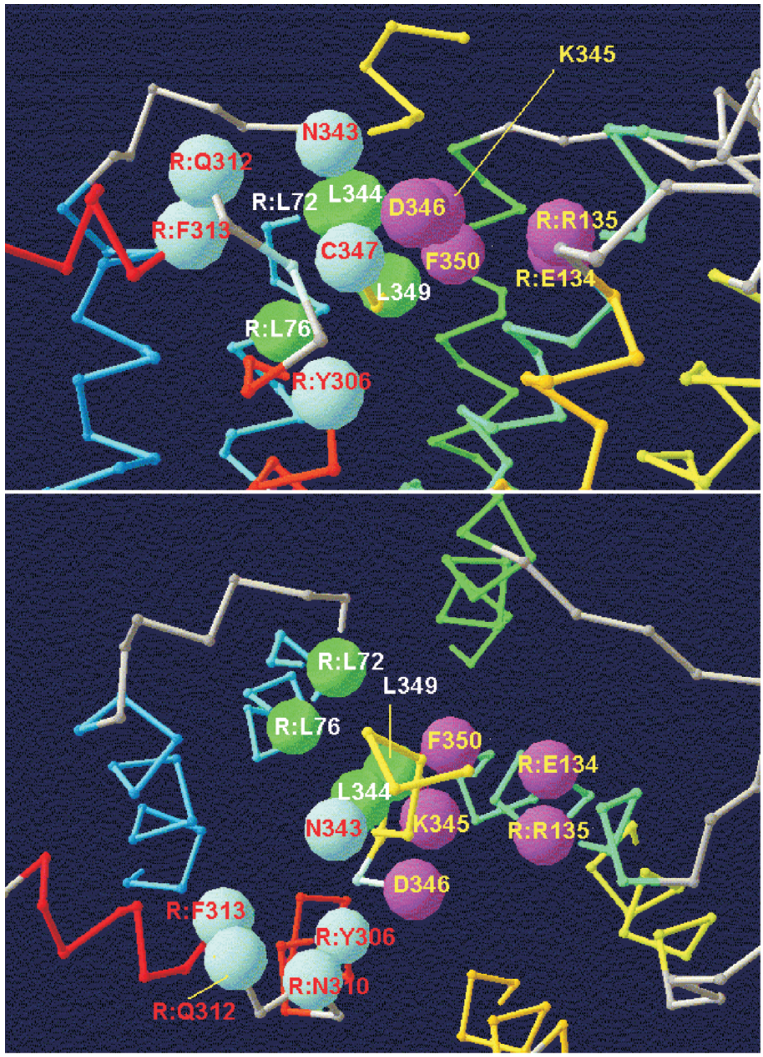

Figure 3. A blow-up of the putative conservative interactions between $\mathrm{Gt}_{\alpha}(338-350)$ peptide and its $\mathrm{RD}^{*}$ putative nest.

Top: a side view, orientation as in Fig. 2; bottom: a top view, orientation as in Fig. 1, bottom. The clusters of conservative, potentially interacting residues are symbolically shown as balls: (i) polar ionic interactions are shown violet; (ii) strictly conservative non-polar ones are shown green; and (iii) conservative polar- $\pi$ aromatic are shown cyan. The labels of the receptor residues begin with "R".

and RD* TM3 E134 and R135 from the ERY motif; (ii) those involving strictly conservative $\mathrm{Gt}_{\alpha}$ L344 and L349 and RD* L72 and L76 in TM2; and finally (iii) $\mathrm{Gt}_{\alpha} \mathrm{C} 347$ and Y306-N310-F314 from the TM7-Helix 8 boundary in $\mathrm{RD}^{*}$.

This fit involves mainly conserved residues in the both parties. Thus, the proposed set of interactions at the cavity-tip interface appears to constitute an interaction core common to the whole Class A GPCR family. This hypothesis goes at least two steps further than a recent one (Oliveira et al., 1999) proposed, when the dark-adapted RD structure was unknown while the general $\mathrm{RD}^{*}$ architec- ture at the Gt interface was less distinctly articulated. First, we doubtless are able to exploit the complete atomic-resolution structure of the $\mathrm{Gt}_{\alpha}$ subunit in a complex with $\mathrm{RD}^{*}$, including the formerly unresolved C-terminus of established structural-functional significance (Martin et al., 1996; Kisselev et al., 1998; Kisselev et al., 1999; Aris et al., 2001; Hamm, 2001; Koenig et al., 2002). Secondly, we are able to hypothesize on the structure of the putative $\mathrm{RD}^{*}$ opening at the $\mathrm{RD}^{*}-\mathrm{Gt}$ interface to more detail than ever so far. It is very fortunate that the coupling of these two new features, modeled on the $\mathrm{RD}^{*}$-Gt interface as described above, seems to be compatible with the coupling of Family A GPCR to its respective $G$ protein. This seemingly general prospect strengthens the present hypothesis. Currently, we are carrying out the unconstrained molecular dynamics (MD) of the raw $\mathrm{RD}^{*}-\mathrm{Gt}_{\alpha}(338-350)$ complex, embedded in a fully hydrated lipid bilayer. At the time of this writing the MD has advanced to about $10 \mathrm{~ns}$. MD of this time-scale would possibly allow for the appearance of tendencies in dynamical structure changes, likely enabling an assessment whether the $\mathrm{RD}^{*}-\mathrm{Gt}_{\alpha}(338-350)$ complex approaches a stable state or is structurally inconsistent. Which would bear on the answer whether this model could suffice to explain the stabilization of $\mathrm{RD}^{*}$ by $\mathrm{Gt}_{\alpha}(338-$ 350 ) or a more advanced one would be required, see below.

On the other hand, it is also clearly seen that this model (actually, any model meeting the 1:1 RD* to Gt stoichiometry) can hardly accommodate the $\mathrm{Gt}_{\alpha}$ and $\mathrm{Gt}_{\mathrm{y}}(50-71)$ farnesyl C-termini for a two-site activation of Gt, see Fig. 2. Were these parallel or sequential interactions (Kisselev et al., 1999), they would require an $\mathrm{RD}^{*}$ oligomer, at least a dimer. Indeed, in recent two papers, extensive oligomerization of $\mathrm{RD}$ (dark-adapted) and its apoprotein, opsin, in rod outer segments (ROS) of mice has been demonstrated (Fotiadis et al., 2003; Liang et al., 2003) using atomic force microscopy (AFM). There are 
also numerous indications that other Family A GPCRs may function as dimers; for a recent review, see (George et al., 2002). As demonstrated by AFM, the RD and opsin molecules alike make extensive and quasi-regular rows of dimers filling most of the membrane surface of ROS (Liang et al., 2003). The authors propose the best fit of the experimental RD structure in this network and simultaneously suggest a putative $\mathrm{RD}^{*}$-Gt complex meeting the $2: 1$ stoichiometry. The RD units interface each other utilizing their TM4 and TM5 in a head-to-head interaction of $\mathrm{C}_{2}$ symmetry and in this disposition admit a Gt heterotrimer. This imposes on Gt an orientation rotated by $\sim 180^{\circ}$ around its vertical axis, relative to that given in Fig. 2. Simultaneously, the dimers form rows utilizing side-to-side interactions between CL3 and CL1, also including respective helices from adjacent dimers. And, finally, the rows run densely enough relative to one another to allow weaker tail-to-tail interactions utilizing TM1 again in the $\mathrm{C}_{2}$ symmetry, from yet different adjacent RD pairs. It is conceivable, given only a minor rearrangements of this assembly network upon activation of $\mathrm{RD}$ to $\mathrm{RD}^{*}$, that the latter tail-to-tail dimer rather than a head-to-head one, could make an operationally active unit meeting the $\mathrm{RD}^{*}$-Gt $2: 1$ stoichiometry and simultaneously being in agreement with Fig. 2. Clearly, both models while compatible with important experimental aspects, need more experimental proof to be confirmed, improved or rejected.

\section{R E F E R E N C E S}

Archer E, Maigret B, Escrieut C, Pradayrol L, Fourmy D. (2003) Trends Pharmacol Sci.; 24: 36-40.

Altenbach C, Klein-Seetharaman J, Cai K, Khorana HG, Hubell WL. (2001) Biochemistry.; 40: 15493-500.

Arimoto R, Kisselev OG, Makara GM, Marshall GR. (2001) Biophysical J.; 81: 3285-93.
Aris L, Gilchrist A, Rens-Domiano S, Meyer C, Schatz PJ, Dratz EA, Hamm HE. (2001) $J$ Biol Chem.; 276: 2333-9.

Ballesteros J, Palczewski K. (2001) Curr Opin Drug Discov Dev.; 4: 561-74.

Ballesteros JA, Shi L, Javich JA. (2001) Mol Pharmacol.; 60: 1-19.

Berman HM, Westbrook J, Feng Z, Gilliland G, Bhat TN, Weissig H, Shindyalov IN, Bourne PE. (2000) Nucleic Acids Res.; 28: 235-42.

Bissantz C, Bernard P, Hibert M, Rognan D. (2003) Proteins.; 50: 5-25.

Bourne PE. (2000) Nucleic Acids Res.; 28: 235-42.

Bourne HR. (1997) Curr Opin Cell Biol.; 9: 134-42.

Case DA, Pearlman DA, Caldwell JW, Cheatham III TE, Ross WS, Simmerling C, Darden T, Merz KM, Stanton RV, Cheng A, Vincent JJ, Crowley M, Ferguson DM, Radmer R, Seibel GL, Singh UC, Wiener P, Kollman PA. (1997) Amber 5.0. University of California San Francisco.

Cherfils J, Chabre M. (2003) Trends Pharmacol Sci.; 28: 13-7.

Ernst OP, Meyer CK, Marin EP, Henklein P, Fu WY, Sakmar TP, Hofmann KP. (2000) J Biol Chem.; 275: 1937-43.

Fahmy K, Jäger F, Beck M, Zvyaga TA, Sakmar TP, Siebert F. (1993) Proc Natl Acad Sci $U S$ A.; 90: 10206-10.

Farrens DL, Altenbach C, Yang K, Hubell WL, Khorana HG. (1996) Science.; 274: 768-78.

Filipek S, Teller DC, Palczewski K, Stenkamp R. (2003a) Annu Rev Biophys Biomol Struct.; 32: $375-97$.

Filipek S, Stenkamp R, Teller DC, Palczewski K. (2003b) Annu Rev Physiol.; 65: 851-79.

Fotiadis D, Liang Y, Filipek S, Saperstein DA, Engel A, Palczewski K. (2003) Nature.; 421: $127-8$.

Fritze O, Filipek S, Kuksa V, Palczewski K, Hofmann KP, Ernst OP. (2003) Proc Natl Acad Sci U S A.; 100: 2290-5. 
George SR, O’Dowd BF, Lee SP. (2002) Nature Rev Drug Discov.; 1: 808-20.

Guex N, Diemand A, Peitsch MC. (1999) Trends Biochemical Sci.; 24: 364-7.

van Gunsteren WF, Berendsen HJC. (1996) Biomolecular Simulation: the GROMOS96 Manual and User Guide. Vdf Hochschulverlag ETH Zürich. (http://www.igc.ethz.ch/gromos/).

Hamm HE. (2001) Proc Natl Acad Sci U S A.; 98: $4819-21$.

Hamm HE, Deretic D, Arendt A, Hargrave PA, König B, Hoffman KP. (1988) Science.; 241: $832-5$.

Hunyady L, Vauquelin G, Vanderheyden P. (2003) Trends Pharmacol Sci.; 24: 81-6.

Iiri T, Fartel Z, Bourne H. (1998) Nature.; 394: $35-8$.

Jorgensen WL, Tirado-Rives J. (1988) J Am Chem Soc.; 110: 1657-66.

Kisselev OG. Downs MA. (2003) Structure.; 11: $367-73$.

Kisselev OG, Kao J, Ponder JW, Fann YC, Gautam N, Marshall GR. (1998) Proc Natl Acad Sci U S A.; 95: 4270-5.

Kisselev OG, Meyer CK, Heck M, Ernst OP, Hoffman KP. (1999) Proc Natl Acad Sci U S A.; 96: 4898-903.

Klabunde T, Hessler G. (2002) ChemBioChem.; 3: 928-44.

Koenig BW. (2002) ChemBioChem.; 3: 975-80.

Koenig B.W, Kontaxis G, Mitchell DC, Louis JM, Litman BJ, Bax A. (2002) J Mol Biol.; 322: 441-61.

Lambright DG, Noel JP, Hamm HE, Sigler PB. (1994) Nature.; 369: 621-8.

Lambright DG, Sondek J, Bohm A, Skiba NP, Hamm HE, Sigler PB. (1996) Nature.; 379: 311-9.

Liang Y, Fotiadis D, Filipek S, Saperstein DA, Palczewski K, Engel A. (2003) J Biol Chem.; 278: 21655-62.

Lu Z-L, Saldanh JW, Hulme EC. (2002) Trends Pharmacol Sci.; 23: 140-6.
Martin EL, Rens-Domiano S, Schatz PJ, Hamm HE. (1996) J Biol Chem.; 271: 361-6.

Mirzadegan T, Benkö G, Filipek S, Palczewski K. (2003) Biochemistry.; 42: 2759-67.

Miyano M. (2001) Pharmacogenomics J.; 1: $225-8$.

Meng EC, Bourne H. (2001) Trends Pharmacol Sci.; 22: 587-93.

Noel JP, Hamm HE, Sigler PB. (1993) Nature.; 366: 654-63.

Okada T, Palczewski K. (2001) Curr Opin Struct Biol.; 11: 420-6.

Okada T, Ernst OP, Palczewski K, Hofmann KP. (2001) Trends Pharmacol Sci.; 26: $318-24$.

Okada T, Fujiyoshi Y, Silow M, Navarro J, Landau EM, Shichida Y. (2002) Proc Natl Acad Sci U S A.; 99: 5982-7.

Oliveira L, Paiva ACM, Vriend G. (1999) Protein Eng.; 12: 1087-95.

Onrust R, Herzmark P, Chi P, Garcia PD, Lichtarge O, Kingsley C, Bourne HR. (1997) Science.; 275: 381-4.

Palczewski K, Kumasaka T, Hori T, Behnke CA, Motoshima H, Fox BA, Le Trong I, Teller DC, Okada T, Stenkamp RE, Yamamoto M, Miyamoto M. (2000) Science.; 289: 739-45.

Röhrig UF, Guidoni L, Rothlisberger U. (2002) Biochemistry.; 41: 10799-809.

Sakmar TP. (2002) Curr Opin Cell Biol.; 14: 189-95.

Saam J, Tajkhorshid E, Hayashi S, Schulten K. (2002) Biophys J.; 83: 3097-112.

Stenkamp RE, Teller DC, Palczewski K. (2002) ChemBioChem.; 3: 963-7.

SYBYL 6.6 (1999) Tripos Inc. 1699 South Hanley Rd, St. Louis MO 63144 U S A.

Teller DC, Okada T, Behnke CA, Palczewski K, Stenkamp RE. (2002) Biochemistry.; 40: 7761-72. 